\title{
O MATERIAL DIDÁTICO NO ENSINO DE LÍNGUAS
}

\author{
Marcos Gustavo Richter \\ mrichter@cal.ufsm.br
}

\section{CONSIDERAÇÕES INICIAIS}

Boas práticas docentes no ensino de línguas exigem que se pense em diversas variáveis didáticas ao planejar, implementar e aperfeiçoar cursos. Professores em geral já estão familiarizados com este conjunto de decisões que se impõem em todo trabalho de educação lingüística a ser levado a sério: análise de necessidades, objetivos, seleção e organização de conteúdo, elaboração, escolha e/ou modificação de materiais didáticos, critérios de avaliação. Há quem acrescente a variável recursos e limitações, embora seja argumentável que ela compareça dispersa e diluída nas demais já mencionadas.

Neste artigo, daremos destaque a uma delas: a elaboração, adoção e modificação de materiais didáticos, tomando por base os trabalhos de Cunningsworth (1995) e Ellis (1997). Os princípios em que se baseiam as considerações a seguir referemse fundamentalmente ao ensino de segunda língua (ou seja, L2 em situação de imersão), porém estamos convencidos de que, no estado atual da questão, há suficientes aproximações entre as premissas pedagógicas de segunda língua e as de língua materna para que o professor de L1 proceda com razoável segurança às adaptações que se fizerem necessárias a seu contexto (Richter, 2000).

Antes, porém, vale lembrar que a adoção e/ou uso de material didático reflete, explícita ou implicitamente, um conjunto de saberes, crenças e pressupostos sobre ensino-aprendizagem de línguas - bem como eventuais dúvidas. Uma das mais típicas, e que merece ser dirimida, é: Devo ou não ensinar gramática? Ellis (1997) aborda esta questão, sem dá-la por resolvida, propondo uma série de recomendações. Ele esclarece que os preceitos sugeridos, ainda que resultantes de investigações sérias sobre aquisição da linguagem, em diversos casos conflituam entre si e por vezes são pouco mais que especulativos. Sendo assim, não constituem regras que pretendam engessar a educação lingüística, e sim um conjunto de princípios para o professor interpretar o que observa no seu ambiente de trabalho e, com base nessas interpretações, tomar decisões as mais adequadas possíveis. Os resultados auferidos da prática constante da pesquisa-ação colaborativa, metodicamente conduzida, ainda são para Ellis a fonte mais confiável de conhecimentos pedagógicos à disposição do docente.

As sugestões que o autor apresenta são:

1. Professores devem, salvo algumas exceções bem determinadas, ensinar gramática - no sentido de focalizar seletivamente elementos formais da língua-alvo e trabalhá-los criteriosamente, associando forma e sentido(s) nas tarefas propostas. 
2. O ensino da gramática dá melhores resultados quando o aluno estiver num nível de desenvolvimento compatível com os itens lingüísticos a ensinar. Este nível deve ser determinado pelo professor (ou por uma equipe docente) por meio de recursos de investigação em sala de aula (por exemplo, pesquisa-ação educacional).

3. A seleção e seqüenciamento dos elementos gramaticais a ensinar - ou, pelo menos, a trabalhar de forma explícita e/ou contínua - também deve ser uma decisão do profissional responsável (ou sua equipe), determinada preferenciamente por meio de recursos de investigação em sala de aula (cabe assinalar, de passagem, a importância do assim-chamado professor reflexivo, particularmente clara nesses dois pontos).

4. Dentre os elementos gramaticais a ensinar, os seguintes critérios de preferência podem ser empregados, ao menos como hipótese inicial de trabalho (a ser reajustada sempre que necessário):

a) A gramática deve focalizar preferencialmente os traços gramaticais que correspondam a propriedades privativas da norma padrão, deixando em segundo plano os traços que sejam comuns a todos ou quase todos os registros e dialetos da língua-alvo.

b) A instrução deve incidir preferencialmente sobre itens não-salientes, ou seja, que não sejam óbvios diante de um exame superficial da forma.

c) Os traços redundantes, ou seja, aqueles que não contribuem em si mesmos para o sentido da mensagem em que ocorrem, devem ser trabalhados ativamente.

d) Os traços marcados, ou seja, que correspondem a uma morfossintaxe particular, mais específica, se beneficiam de um trabalho didático mais focalizado, sem que se descuidem, claro, dos não-marcados.

e) Em se tratando do ensino de regras gramaticais, convém priorizar as regras poderosas, isto é, sem ou com raras exceções. Já quando uma propriedade gramatical se expressar singularmente (como em regência verbal), pode ser oportuno deter-se nela como uma particularidade relevante.

5. É aconselhável empregar não uma técnica didática apenas, mas um leque de opções, cuja pertinência e eficácia também devem ser avaliadas por investigação em sala de aula. Vale aqui lembrar que princípios (ou paradigmas de educação lingüística) são uma coisa; métodos ou técnicas, outra, muito diferente. Podemos ilustrar com um exemplo: um psicólogo pode adotar um entre vários paradigmas (ser freudiano, junguiano, maslowiano etc.); mas tem à sua disposição, como os demais profissionais da sua área, o Teste de Rorschach, que pode empregar se ou quando quiser, a seu critério.

6. Algumas considerações ainda merecem ser feitas com relação às opções metodológicas que o professor venha a adotar no uso do material selecionado:

a) O feedback do processo de ensino-aprendizagem, ou seja, dar ao aluno a noção de estar se aproximando em maior ou menor grau dos objetivos estabelecidos, decididamente melhora o aprendizado, sendo que isto vale tanto para o explícito quanto para o implícito.

b) $\mathrm{O}$ feedback pode ir-se tornando gradativamente implícito à medida que o nível de desempenho do aluno vai aumentando.

c) Elaborar atividades centradas em itens gramaticais específicos é tarefa mais difícil para fins de produção textual do que para fins de compreensão. 
d) Instruções explícitas (o professor emprega metalinguagem gramatical) e implícitas (o aluno manipula reflexivamente itens gramaticais) são, ambas, proveitosas para o ensino de línguas, cada uma a seu modo. Instrução explícita é mais eficaz se a regra a ser aprendida é complexa e a informação fornecida é ilustrada com exemplos.

e) Com respeito ao ensino indutivo (dos casos ou exemplos à regra ou generalização) ou dedutivo (da regra ou generalização aos casos ou exemplos), empiricamente não se provou que um desses processos cognitivos seja inerentemente superior ao outro. O trabalho com ambos, acompanhado de uma correta atitude investigativa para optar convenientemente, é ainda a melhor opção.

f) A estratégia de insumo intensivo (expor o aluno massivamente a material contendo as estruturas focalizadas) funciona melhor quando se centraliza em estruturas relativamente simples e que não se achem já erroneamente representadas na interlíngua dos alunos. Em conseqüência, isoladamente empregada contribui para o aprendizado de estruturas novas, mas não para a erradicação de incorreções estruturais já existentes. Para obter este segundo resultado, é recomendável agregar instrução explícita.

\section{A ADOÇÃO DE MATERIAL DIDÁTICO}

Geralmente se admite que a função do livro didático é estar a serviço de professores e alunos sem exercer uma função tirânica como árbitro do conteúdo do curso ou dos métodos de ensino. O relacionamento entre professor e livro é algo importante a considerar e o melhor papel deste último consiste em uma parceria que compartilhe objetivos comuns, cada lado trazendo sua contribuição especial. Livros têm múltiplos papéis em ensino de línguas e podem servir como:

- Recurso para apresentação de material (falado e escrito)

- Fonte de atividades para prática do aluno e interação comunicativa

- Fonte de referência para alunos em gramática, vocabulário, pronúncia, etc.

- Fonte de estímulo e idéias para atividades de língua em sala de aula

- Programa (em que esses materiais refletem os objetivos da aprendizagem que já tenham sido determinados)

- Recurso para uma aprendizagem direcionada ao eu ou o trabalho de acesso ao eu

- Apoio para professores menos experientes que tenham ainda que ganhar confiança

Há muitos critérios que podem ser usados para avaliar livros. Contudo, para propósitos práticos será necessária uma lista manejável dos critérios mais importantes. Como critérios diferentes aplicam-se em diferentes circunstâncias, é melhor que o professor identifique suas próprias prioridades e prepare sua própria lista, talvez usando alguns dos critérios aqui expostos e adicionando outros pessoais. 
Um livro (ou pacote ou coleção didática) para ensino de línguas será tanto melhor quanto mais satisfizer aos requisitos abaixo:

1. Os objetivos coadunam-se ao programa de ensino, às necessidades dos alunos e ao contexto de utilização.

2. O livro cobre a maioria dos itens necessários ao curso, é adequadamente organizado - quanto a estruturas, funções, conteúdos, habilidades - para alunos e professores, apresenta-se consistentemente seqüenciado (complexidade dos itens, exigências de aprendizagem, utilidade etc.) e inclui material e ocasiões para trabalhar habilidades integradas.

3. A proposta didática amolda-se a diferentes estilos de ensino e aprendizagem - sendo desejável que algo do material seja direcionado para estudo personalizado.

4. O livro distribui adequadamente os itens gramaticais segundo níveis compatíveis de competência lingüística e compatibiliza-os com as necessidades dos alunos, focaliza formas, funções e usos além do nível da sentença (baseia sua racionalidade didática em textos e gêneros), trabalha variedades sociolingüísticas, estilo, fatores sócio-culturais e contextuais.

5. O vocabulário é bem selecionado e dosado, com ênfase no desenvolvimento de vocabulário e nas estratégias para a aprendizagem individual do léxico.

6. Atividades de leitura englobam material suficiente, são adequadas para o nível e interesses de seus estudantes, procuram otimizar estratégias de leitura e habilidades correlatas.

7. Atividades de escrita orientam e controlam os processos de produção textual em suas várias etapas, inclusive fornecendo apoio à organização de pedaços mais longos de escrita (como parágrafos), equilibram correção e adequação, sensibilizam o aluno aos diferentes estilos.

8. Os conteúdos temáticos são variados, de interesse genuíno para os aprendizes, abordados numa perspectiva intercultural, - ou seja, grupos são representados e/ou problematizados com referência a gênero, etnia, classe social, profissão, faixa etária, deficiências etc - e ensejam debate suficientemente sofisticado, respeitando, porém, o nível lingüístico dos aprendizes.

9. A metodologia é cientificamente consistente, envolve ativamente o aprendiz embora respeitando os estilos de aprendizagem de seus alunos e suas expectativas - , emprega estratégias adequadas para explicitação e assimilação de fatos lingüísticos, inclui conselhos ou tutoramentos para os estudantes quanto ao emprego de estratégias metacognitivas e habilidades de aprendizagem e predispõe os aprendizes a assumirem certo grau de responsabilidade por sua própria aprendizagem e êxito.

10. Os autores (designers) apresentam e justificam as premissas e princípios básicos que fundamentam o material, orientam os professores que estarão usando o livro e seus materiais auxiliares, fornecendo-Ihes apoio que englobe técnicas de ensino e itens de linguagem tais como regras de gramática e informação específica sobre cultura.

A avaliação do livro pode acontecer antes, durante ou depois de seu uso, dependendo das circunstâncias e os propósitos para os quais está sendo realizada. A avaliação de pré-uso, embora provavelmente a mais comum, é também a modali- 
dade mais difícil, uma vez que não há experiência real de uso do livro para ajudar nas decisões. Neste caso, estamos olhando para o futuro ou para a realizaçãoapresentação potencial do livro, e, de certa forma, qualquer decisão sobre o material acaba se tornando uma espécie de aposta. Já a avaliação em uso diz respeito à avaliação do livro enquanto está sendo empregado nas aulas, e ocorre quando se torna necessário decidir sobre alguma adoção ou mudança no início ou no transcorrer do curso - como no monitoramento probatório ou na reavaliação por defasagem parcial. Por último, a avaliação de pós-uso fornece avaliação retrospectiva da "pilotagem" já realizada - e considerada completa ou suficiente - de um livro, permitindo identificar vantagens e desvantagens manifestas durante um período de uso constante e tomar decisões sobre a continuidade do uso do material. Pacotes didáticos fechados geralmente se avaliam desta maneira.

Não convém adotar um livro ou coleção sem antes verificar se o perfil da clientela é condizente com a proposta dos autores do material didático, através de uma análise de necessidades e de recursos, como a que segue:

- Qual é o "status" e o papel da língua-alvo para a clientela?

- Quais são as principais razões da clientela para aprender a língua-alvo?

- Que carga horária está prevista? Que tempo para atividades complementares ou extra-classe é disponível? O programa é extensivo ou intensivo?

- Qual é o tamanho da turma? As turmas são homogêneas com respeito à idade, nível, habilidades (e outros fatores) dos alunos?

- Que recursos se acham disponíveis para o trabalho didático, incluindo espaço físico apropriado, recursos tecnológicos (tevê e vídeo-cassete, computadores e Internet, laboratório de línguas), materiais complementares, acesso a fotocópia? A infraestrutura se acha em boas condições para se trabalhar?

- Quais as idades, níveis, expectativas, motivação da cientela?

- Quais são seus interesses, tabus, valores, background cultural?

- Qual é a experiência prévia da clientela em aprender uma língua? Em aprender a língua-alvo? Quais são os estilos de aprendizagem preferidos pelo alunado? No caso da língua materna, que experiência os aprendizes tiveram e têm com relação à leitura, à escrita, à norma padrão em seu ambiente familiar e social?

\section{ADOÇÃO. ADAPTAÇÃO. CRIAÇÃO.}

O lugar ocupado pelos livros didáticos na educação lingüística pode variar consideravelmente, refletindo o tipo de relação mediadora que o material estabelece entre o professor e o processo de ensino-aprendizagem, ou melhor, o maior ou menor grau em que o professor se subordina ao livro - variável esta até certo ponto influenciada pela abordagem básica do sistema educacional em que o profissional está inserido.

Em um dos pólos - adoção do livro e subordinação irrestrita a ele - o conteúdo é ministrado com fidelidade e na ordem exata de apresentação: cada texto, cuidadosamente estudado; cada exercício, meticulosamente trabalhado. Essa aborda- 
gem escolar é típica de países em que a elaboração do programa é centralizada e um livro tem aprovação e prescrição oficial. Mas uma situação semelhante se observa em cursos intensivos ou com equipes docentes de pouca experiência. Nestes casos, uma maior expectativa de êxito repousa sobre o mito da "infalibilidade" da planificação do trabalho, restringindo drasticamente as opções técnicas e prescrevendo instruções claras e diretas ao professor. Por um lado, esse "engessamento metodológico" resolve aceitavelmente a escassez de equipes qualificadas; mas, por outro lado, transfere ao livro muito da responsabilidade pela qualidade do ensino.

Esta dependência acentuada do professor em relação ao material didático apresenta diversas desvantagens, das quais se destacam:

- Falta de variedade nos procedimentos de ensino.

- Reduzida adaptação às necessidades e problemas.individuais do estudante.

- Falta de espontaneidade na interação professor-aluno e aluno-aluno.

- Drástica redução da criatividade na técnica de ensino e no uso da língua.

- Redução da importância das contribuições que bons professores são capazes de fazer em todos os níveis no processo de aprendizagem.

Apesar disso, em casos específicos, a adoção de programas, materiais e procedimentos rígidos pode ser a alternativa de eleição, sacrificadas algumas vantagens, como as já mencionadas.

Um relacionamento mais balanceado entre professor e livro se observa em contextos de adaptação de materiais, ou seja, onde professores são capazes de selecionar material de uma escala de cursos alternativos, ou onde, apesar da existência de um livro básico, este é apoiado por uma variedade de materiais complementares (que o professor pode produzir, corrigindo lacunas). Em situações desse tipo, mesmo que haja um livro principal - escolhido pelos próprios professores ou pela instituição para servir de roteiro básico de seqüenciamento - ele é usado seletivamente, complementado por outro material na medida do desejável.

Uma abordagem deste tipo apresenta diversas vantagens:

- Assenta-se sobre uma estrutura comum - digamos, pré-seqüenciamento de literatura e gramática normativa - fornecida pelo livro.

- Estabelece limites para a criatividade de professores menos experientes e ao mesmo tempo lhes dá oportunidade para desenvolverem-se profissionalmente, uma vez que se tornam menos dependentes de livros e ganham confiança para experimentar materiais alternativos, inclusive criados por eles próprios.

- Viabiliza a recombinação de partes mais fracas do livro padrão com partes de outros livros ou o emprego de material próprio produzido para se adequar ao contexto específico de ensino.

- Contribui para uma maior variedade de atividades e técnicas, diminuindo a desmotivação dos alunos.

- Propicia uma resposta mais flexível às necessidades individuais, contribuindo assim para personalizar mais a relação professor-aluno. 
Por fim, no outro pólo da relação professor-material, podemos encontrar escolas com um programa, mas nenhum livro estabelecido. Os professores, trabalhando dentro de um programa global e eventualmente em parcerias, constroem suas próprias aulas e seqüências de aulas a partir de um grande conjunto de materiais publicados, internos e produzidos individualmente. Alguns docentes podem achar tal liberdade e responsabilidade assustadora, enquanto outros podem revelar seu talento profissional nela. Trata-se de uma abordagem potencialmente muito gratificante, na medida em que abre espaço à criatividade, flexibilidade e originalidade

dos professores. É, contudo, exigente, desgastante e grande consumidora de tempo.

\section{PARÂMETROS DE QUALIDADE NO LIVRO DIDÁTICO}

\subsection{O Conteúdo Lingüístico}

Parte-se de um princípio: uma análise de necessidades, ou se quisermos, de perfil de alunos, permite estabelecer o que os estudantes precisam aprender e esperam aprender. Será em função disso que avaliaremos o conteúdo lingüístico de um livro, isto é, o que ele, de modo mais ou menos manifesto, se dispõe a ensinar em termos de gramática - aqui entendida não apenas como normativa, mas também como descritiva ou descritivo-reflexiva, esta última denominada por alguns "foco na forma" - e vocabulário - aqui incluída fonética-fonologia, principalmente em língua estrangeira ou segunda língua, quando faz parte das habilidades áudioorais. Mas há toda uma diversidade de aspectos da língua-alvo apta a fazer parte da educação lingüística, e que se entrelaçam de maneira complexa: funções, tópicos, estratégias comunicativas, gêneros, questões culturais, entre outros.

É um fato incontroverso que um programa de curso, salvo exceções muito específicas, não pode ser planejado exceto dividindo-se o sistema lingüístico em unidades didaticamente discretas para o ensino e a aprendizagem efetivos ocorrerem. Porém vale lembrar que é decididamente complicado separar aspectos individuais da língua - encarada como um todo sistêmico, que opera em vários níveis simultânea e integradamente - e isolá-los sem comprometer ou mesmo perder a autenticidade e naturalidade do processo comunicativo natural. Mais precisamente, em um uso autêntico, os falantes têm de expressar o que querem dizer através dos sistemas gramatical, lexical e fonológico da língua ao mesmo tempo e também precisam selecionar estratégias discursivas apropriadas para o tópico, o contexto e o propósito desejados - enquadrar-se em um ou mais dos diferentes gêneros vigentes como práticas sócio-culturais. Os usuários devem igualmente interpretar o que está sendo dito a eles, usando estes mesmos processos, mas de um modo reverso. Claramente, o todo da língua em funcionamento é maior e mais complexo do que a mera soma de suas partes tomadas em si mesmas. Isto até certo ponto explica por que projetar materiais é um problema complexo no ensino de línguas. 
Decorre disso que uma das questões mais fulcrais para professores e designers de materiais é o quanto uma língua pode ser analisada e fragmentada sem perder sua natureza e identidade - ou ao menos sem impedir que as atividades didáticas focais impeçam professor e aluno de re-ligarem as partes entre si e as partes com o todo. Passaremos a examinar, num primeiro momento, o problema da gramática incluída no curso e, num segundo momento, o do vocabulário.

\subsubsection{Gramática}

Ao introduzir novos itens gramaticais, é possível ensinar a forma de um novo item gramatical de forma mecânica, sem seu significado - embora isso seja desaconselhável na maioria dos casos. Porém é possível - e agora recomendável de modo geral - apresentar um novo item da gramática com ênfase em seu uso, minimizando ou adiando os problemas apresentados por sua forma. Mas tanto a estratégia expositiva forma $\Rightarrow$ uso quanto sua simétrica uso $\Rightarrow$ forma não cobrem isoladamente todos os contextos de ensino-aprendizagem previsíveis, devendo 0 professor estar atento ao nível do aluno e à natureza do item a ser aprendido.

Para ilustrar, na aquisição de língua materna escrita (letramento), quando o aluno já ultrapassou a fase de aquisição mecânica da leitura e da escrita - fase esta na qual os mecanismos de decodificação tomam a maior parte da memória operacional - e já pode ler e escrever preocupado com o conteúdo - é mais indicado privilegiar a direção uso $\Rightarrow$ forma; mas em séries iniciais ou em letramento de adultos - quando o processo de leitura e escrita é automonitorado e ainda não se automatizou - o inverso (forma $\Rightarrow$ uso) pode ser a melhor tática. É, contudo, indiscutível que ambos, forma e uso, devem ser aprendidos tão próximos quanto possível no programa de curso.

Em certos casos, a forma a ensinar não é tanto um problema enquanto forma, mas seu uso pode ser particularmente difícil de assimilar porque envolve conceitos abstratos. Por exemplo, em português como língua materna, itens de conceituação mais complexa incluem papéis temáticos das expressões nominais, aspecto verbal, nominalizações, conectores lógico-semânticos, operadores argumentativos. Em outros casos, o problema pode ser resolvido, em boa parte, ao verificar se a entidade que está sendo referida já é conhecida e identificável ao ouvinte, ou seja, se faz parte de seu conhecimento prévio ou não, como é o caso das expressões estereotipadas da língua-alvo.

\subsubsection{Vocabulário}

O ensino do vocabulário tem resgatado seu devido reconhecimento nas últimas décadas, na medida em que não só a comunicação sustentada quanto os processos cognitivos mais refinados tornam-se tarefas virtualmente impossíveis sem acesso a um vocabulário relevante e razoavelmente amplo (Garcia,1988). A seleção de vocabulário a ensinar não é assunto tão simples quanto se poderia imaginar. Um critério básico, digamos freqüência ou utilidade, é insuficiente para sele- 
cionar uma gama operacionalizável de vocabulário para programas de ensino ou livros. Diga-se de passagem que estes raramente esclarecem como foi feita a seleção-inclusão do vocabulário para além de declarações genéricas relativas à freqüência e à utilidade; e, para agravar o quadro, em materiais de português como língua materna, nem mesmo essas considerações rudimentares costumam aparecer.

Uma estimativa otimista para um curso seria de umas 1000 novas palavras ensinadas em cada estágio de 120-140 horas de trabalho em um curso multiestagiado - ou seja, em um curso de 3 horas semanais, ao redor de 20 a 25 palavras novas semanalmente. Freqüentemente atividades adicionais são fornecidas no livro de exercícios dos estudantes, mesmo que essa aprendizagem venha a acontecer fora da sala de aula - haja vista que, do gigantesco acervo lexical da língua-alvo, só mesmo uma pequena fração pode estar presente em qualquer livro didático.

Além de ampliar o vocabulário, materiais didáticos bem formulados podem fornecer aos alunos ferramentaria cognitiva apta para enriquecimento de vocabulário a posteriori - por exemplo, os alunos poderão seguir pistas da relação palavracontexto e/ou decompor palavras em seus morfemas e testá-los no entorno textual. Caso esses livros se esmerem em a) sensibilizar os estudantes ao sistema de vocabulário da língua-alvo - visto inclusive em termos de reconhecimento de classes e funções das palavras - ; b) encorajar habilidades de emprego inteligente do dicionário - de definições, de sinônimos, analógico, etimológico - ; e, finalmente, c) levar a refletir sobre técnicas efetivas de aprendizagem lexical, então teremos uma obra meritória voltada ao desenvolvimento da autonomia discente.

É desabonador para um material didático propiciar meramente listas de palavras ou definições do dicionário de novas palavras. Um agravante disso seria fornecer, em cada texto de uma unidade de leitura, listas de palavras "pré-procuradas", que passivizam o aluno ao desestimulá-lo ao uso do dicionário - sem falar nas palavras ensinadas em isolamento ou fora de contexto, que desestimulam o uso de pistas contextuais. Ao contrário, um aprendizado reflexivo e profícuo deve incluir atividades destinadas a sensibilizar os estudantes para: a) a estrutura do léxico e para as várias relações gramaticais, funcionais e morfêmicas nele embutidas, isto é, os relacionamentos de forma ou composicionais das palavras; b) as relações semânticas que grupos de palavras podem contrair de acordo com a rede de significado - sinônimos, hipônimos, hiperônimos, oposições; c) as relações contextuais, ou seja, conjuntos de palavras associadas a situações particulares, como esporte, alimentação, habitação etc.; d) as expressões estereotipadas, ou seja, palavras comumente encontradas em associação sintagmática e funcional fixa, como: "por via das dúvidas...", "o objetivo deste trabalho é..." etc.; e) a distinção proveitosa entre vocabulário ativo e passivo, que consiste, no ensino de leitura, em abordar estrategicamente o vocabulário da unidade didática em termos de palavras para reconhecer e palavras para empregar.

\subsection{Discurso}


Além das regras da gramática normativa e das propriedades da sentença, o livro didático apresenta, conscientemente ou não, alguns modelos de discurso, cujas regularidades refletem determinações sócio-histórico-culturais que regem os usos da língua e as convenções que estruturam a comunicação efetiva. Essas regularidades, equacionadas em termos da relação entre traços lingüísticos, padrões contextuais e atividades sociais orientadas, constituem os gêneros textuais.

Neste domínio - diretamente relevante para a abordagem comunicativa - estão incluídas áreas tais como relações interfrásticas, coesão e coerência textual, paragrafação, estruturação do texto, relações entre marcas gramaticais e condições sociais de produção, análise da conversação, entre outras. O melhor modelo para $o$ aluno é o texto autêntico. Mesmo tendo em mente que um texto pode ser trabaIhado em vários níveis de complexidade, dependendo do nível de competência gramatical e comunicativa dos alunos, ele deve exibir algumas características verossímeis para um determinado gênero - regularidades dentre as quais, em um nível mais formal da língua, estruturação coerente de conteúdo, paragrafação e uso apropriado de instrumentos coesivos, aqui incluídos pronomes para referência anafórica e conectivos diversos associados a uso semântico-pragmático natural. Os instrumentos organizadores de texto merecem particular atenção, na medida em que agem como instrumentos de sinalização dos sentidos e ajudam os leitores e ouvintes a fazerem seu percurso cognitivo ao longo de uma seqüência discursiva, relacionando sentenças umas com as outras a fim de fazer sentido com o que já foi lido ou ouvido e prever o que está vindo a seguir.

Quanto à relação entre idéias em nível local e entre partes do todo, estratégias e práticas sobre escrita de parágrafos e estruturação de um texto mais longo em parágrafos e segmentos maiores é fundamental. Esta é uma área em que não há regras rígidas como as da gramática normativa, entrando em cena regularidades de desenvolvimento macrossemântico e argumentativo Uma dosagem combinada de explicação e aconselhamento graduais ilustrados por exemplos pode contribuir para um ensino mais ágil e produtivo. Já em um nível mais discursivo, convém que o livro apresente material sobre a organização de diferentes tipos de produção escrita, tais como narrativas, relatórios, cartas e outros, cada qual com seus propósitos, estilo, conteúdos viáveis, público-alvo, contextos de funcionamento. Convenções de gêneros diferentes devem ser adequadamente explicitadas.

Visto que entendemos aqui a linguagem como prática social, e queremos que nossos alunos também o façam, uma dupla tarefa aparece diante deles: perceber e entender a natureza das situações sociais em que se encontram e selecionar e usar os níveis de linguagem apropriados. Um aspecto da tarefa é não lingüístico e o outro lingüístico, mas estes - tal como ocorre com língua e cultura - estão tão intimamente conectados que não é possível negligenciar nenhum. Com efeito, a língua é muito sensível ao seu contexto de uso e é estilisticamente variável. Nós devemos examinar livros do ângulo da adequação para ver até que ponto preparam alunos para usarem estilos apropriados em situações variadas. Falantes fazem uso de estilos diferentes da língua para comunicar em um modo que complementa o significado mais literal das palavras e sentenças. Por exemplo, a ado- 
ção de um estilo informal de discurso ou escrita é uma declaração sobre o relacionamento que existe entre as pessoas que estão se comunicando umas com as outras.

No livro didaticamente bem elaborado, o designer procura chamar a atenção para diferenças estilísticas materializadas em traços de construção gramatical, escolha de vocabulário, estrutura do discurso e eventualmente pronúncia. Ninguém ignora, por exemplo, que, em termos de discurso, a estrutura de um pronunciamento formal é muito diferente daquela de uma conversa entre amigos, ou que, similarmente, uma carta informal é estruturada e proposta diferentemente de uma carta de negócios.

Como norma geral, recomenda-se: a) em um nível elementar, principalmente foco na forma gramatical, podendo também significar ênfase na microestrutura (processos ascendentes); b) em um nível intermediário, maior ênfase tanto no uso apropriado dessas formas para a construção dos sentidos quanto no desenvolvimento de vocabulário, encarado como um conjunto de estratégias cognitivas (processos ascendentes e descendentes balanceados); c) em um nível avançado, abordagem aprofundada da estrutura textual e dos gêneros e suas variáveis (processos descendentes).

\subsection{Seleção, Classificação e Gradação do Conteúdo}

\subsubsection{Premissas da organização do conteúdo}

Embora um programa possa ser conceituado no sentido amplo como um conjunto de especificações sobre o trabalho a ser realizado durante um período de tempo delimitado, há duas premissas fundamentais que servirão como ponto de partida: a) O programa é visto em termos de processo e não como um encadeamento controlado de produções discentes. Essa é uma concepção alternativa de design baseada, não em uma lógica de conteúdo, mas sim em conceitos e proposições atinentes a processos de aquisição e aprendizagem. Quando eventualmente esse programa é adotado em estado puro, conteúdo e objetivos, ao invés de serem préespecificados, são determinados e negociados com os alunos no contexto, ao longo do curso, e a seqüenciação é conseqüência desse mútuo entendimento. Digase de passagem que livros didáticos não participam da elaboração e desenvolvimento do programa-processo - exceto como fontes ad hoc de tarefas isoladas e de alguns recursos específicos - visto que, mesmo com o seqüenciamento não obedecido, seus conteúdos permanecem ainda preestabelecidos.

b) O programa é concebido da maneira oposta à anterior: o output do aluno é a base da organização do curso. Trata-se da maneira mais usual de planejar. Neste caso, o conteúdo de língua será organizado de alguma forma, sendo seqüenciado de acordo com certos princípios básicos ou teorias, tácitos ou explicitados. Eventualmente, o designer pode especificar o tempo gasto em cada atividade ou seção. 
Hoje, entretanto, já existem no mercado materiais adaptáveis ao contexto, prédirecionados para conferir certa flexibilização no uso, inclusive sem fixar rigidamente pontos de partida e de chegada no conteúdo. Programas de aprendizagem sob medida para as necessidades do aluno, atividades de auto-acesso ou ainda adaptação a cursos de diferentes dimensões são alguns dos benefícios que um programa pré-flexibilizado pode oferecer.

Passamos a examinar as opções de programas baseados no conteúdo (de conteúdo preestabelecido). O conteúdo no design do programa pode basear-se predominantemente em:

a) Forma (base estrutural)

b) Função (base nocional/funcional)

c) Situação (base contextual)

d) Tópico ou Tema (base informacional)

Quando dizemos "predominantemente", isso significa que o conteúdo baseia-se em uma combinação desses quatro fatores, cada qual em maior ou menor grau, balanceados de múltiplas maneiras, o que explica de certo modo uma certa heterogeneidade das propostas.

\section{Programa estrutural}

- Abordagem tradicional

- Preocupação em esgotar os fatos gramaticais da língua-alvo

- Enfase na estrutura gramatical, secundarizada pelo léxico dicionarizado

- Seleção e seqüenciamento baseados no roteiro expositivo da gramática normativa

- Escassa consideração dada ao significado ou ao uso das formas

- Ausência de teorias lingüísticas ou de aquisição como suporte pedagógico

\section{Programa nocional-funcional}

- Abordagem pragmática (atos de fala ou funções comunicativas)

- Seqüenciação conforme a utilidade para o aluno (de acordo com a maior ou menor necessidade nas situações de uso)

- Objetivos gerais de aprendizagem podem ser identificados em termos que fazem sentido para os alunos

- Curso com resultados práticos e imediatos, já que os estudantes podem usar e praticar fora da sala de aula mais precocemente o que aprenderam

- Critérios de inclusão em grande parte subjetivos, pois as funções não formam um sistema finito inter-relacionado, nem têm sido completa e compreensivamente descritas

- Programa baseado em funções, porém escassamente centrado em estratégias, que não se deixam inventariar de modo objetivo e finito 
Quando, num programa, comparecem as perspectivas estrutural e funcional conjuntamente, mostram-se complementares e não opostas, pois o curso estabelece os nexos entre forma e função na medida em que mostra como as funções comunicativas, correspondentes às necessidades comunicativas dos alunos, são realizadas através das formas gramaticais apropriadas - propiciando, desta forma, aos alunos, um acervo de unidades de comunicação associadas a unidades formais.

\section{Programa situacional}

- Situações do mundo real (padrões contextuais da cultura) constituem um princípio organizador para selecionar e classificar o insumo lingüístico-comunicativo, ou seja, as formas são situadas e praticadas em contextos norteadores

- Fatores geralmente considerados são: a) participantes (papéis); b) situação (contexto imediato); c) objetivos ou propósitos comunicativos - cultura no sentido amplo (tradições, história, mitos, identidades etc.) geralmente não recebe ênfase

- Situações selecionadas, assim como a língua ensinada, tendem a ser geralmente restritas e previsíveis - deixando de fornecer as bases para uso posterior da língua em situações francamente diversas das abordadas

- Gramática, vocabulário e outros elementos formais derivam das situações selecionadas e não são critério de seleção. Em decorrência, o programa, por ser muito atado a situações específicas, não assegura que as estruturas sejam trabaIhadas com suficiente abrangência

\section{Programa temático}

- Baseado no princípio de que estudantes podem aprender melhor uma língua quando estão focalizando o conteúdo (informação) apresentado ao invés de abordar a língua em si mesma

- Temas geradores constituem fundo organizador de um programa multidimensional (gêneros, funções, formas) e mantêm o interesse e a motivação na medida em que dizem respeito à vida real e às expectativas e problemas dos alunos

- Tópicos ajudam a criar uma sensação de consistência dentro das unidades de curso individuais - consistência esta que certos materiais de ensino do português-língua materna não apresentam, por trabalharem as habilidades de forma fragmentária

- Tópicos permitem interdisciplinaridade e integração com a vida real dos alunos — na verdade embutem um "currículo implícito", representando explicita ou implicitamente valores sócio-culturais, identidades, atitudes - desde que os assuntos sejam desafiadores e condizentes com a idade dos alunos e suas questões relevantes

\section{Programa de curso e ensino comunicativo}

Uma abordagem genuinamente comunicativa é aquela que não somente objetiva ensinar os recursos e as estratégias de comunicação na língua-alvo, mas também 
estimula a comunicação efetiva a respeito de tópicos relevantes e promove a interação genuína entre seus usuários. Infere-se disso que não há como separar o ensino genuinamente comunicativo do ensino sócio-interacionista: podem até ser considerados, de certa forma, sinônimos.

Para tanto, interatividade e autenticidade de material entram em relação sinérgica, apoiando-se mutuamente. A interatividade didática coloca o aluno em melhores condições de, em longo prazo, desenvolver na língua-alvo opiniões bem formadas e expressá-las adequadamente; formar e comunicar com eficácia suas próprias inferências e conclusões; problematizar e discutir pontos polêmicos, fundamentando seus pontos de vista; influenciar e receber influência dos outros. Os benefícios da autenticidade de material estão em criar condições efetivas (embora haja outros fatores em jogo) para um output também autêntico: informar, desafiar, estimular e enriquecer a experiência, encorajar a curiosidade, desenvolver julgamentos. Porém ressalvamos que o conteúdo não precisa necessariamente ser abstrato ou intelectual, pois o relato de casos exemplares, o humor, a literatura também fazem parte da cultura ordinária ou cultivada, e portanto têm seu lugar no programa como parte de um amplo leque de gêneros a serem trabalhados integradamente.

\subsubsection{Critérios de Seqüenciamento do Conteúdo}

Uma vez que o designer tenha estabelecido o centro gerador do seu programa forma gramatical, função comunicativa, situação norteadora da prática lingüística ou assunto para o qual as práticas lingüísticas são um meio - trata-se de seqüenciar as unidades de trabalho. O seqüenciamento conceitua-se como a ordem em que novos itens são ensinados, como os componentes se entrelaçam e como a língua ensinada se desenvolve progressivamente. Embora, o seqüenciamento seja inerente ao programa e à maioria dos livros, há poucos princípios reconhecidos para orientação de designers, e estes se baseiam em critérios heterogêneos, incluindo tradição e intuição. Geralmente os elementos lingüístico-comunicativos abordados se distribuem em:

- Forma - Gramática e Vocabulário

- Função - Noção acrescida como base semântica

- Contexto - Situações e Tópicos

- Habilidades - destaque variado à Oralidade em L2

De acordo com a preocupação maior ou menor do designer em revisar, reciclar e ampliar a complexidade de unidades de curso, este pode se subdividir (tendencialmente) em linear e cíclico. Um curso com progressão linear adota uma ordem de apresentação que lida com cada item de língua exaustivamente antes de passar para o próximo. Compartimenta estanquemente cada parte, não se preocupando com revisão e integração em unidades posteriores. Não nos referimos aqui à revisão como simples "recordação" no final de um ano ou semestre, e sim como retomada integrativa posterior do item em níveis e usos lingüísticos mais complexos. 
Já uma progressão cíclica implica, num primeiro momento, passar ágil e superficialmente de um item de língua para outro e, num segundo momento, efetuar movimentos metódicos de retorno para cada componente numa espiral crescente de complexidade, ampliando a compreensão do mesmo e entrelaçando-o com um número cada vez maior de elementos adjacentes. Esta opção é mais condizente com o conceito de língua como sistema.

Outra maneira de classificar a arquitetura geral de curso (Dubin e Olshtain, 1990), que não se choca com os critérios antes mencionados, é a seguinte:

- FORMATO ESTRUTURAL - Tradicional, acompanha o formato de uma gramática normativa e tem como objetivo tácito fazer saber o conjunto de regras e formas contidas naquela. É basicamente não-comunicativo, pois o saber-o-quê prevalece sobre o saber-como (ou seja, a ênfase na metalinguagem "sufoca" o desenvolvimento das habilidades).

- FORMATO CÍCLICO - Especialmente recomendado para a construção de conceitos e habilidades de forma gradativa. Combina muito bem a pedagogia centrada no processo com a centrada no produto. Quando a situação não é a de curso livre (ensino oficial), precisa em geral mesclar-se com outros formatos.

- FORMATO MATRICIAL - Recomendado para tópicos multiperspectivados e/ou que privilegiem o enfoque intercultural, é apto para criar espaços de debate. Opção de escolha quando o programa procura basear-se em tópicos e gêneros sem, porém, perder de vista as formas e funções. Pode ser combinado com o formato cíclico, a critério do designer.

- FORMATO STORY-LINE - Baseado em uma série de episódios narrativamente ligados entre si. Por inserir um "fio de continuidade" contextual ao curso, este formato é recomendável para alunos que se beneficiam de contextualização dos tópicos e ativação de processos identificatórios. É facilmente hibridizável, ou seja, mescla-se com uma ampla variedade de abordagens didáticas.

- FORMATO MODULAR - Espécie de "caixa preta negociada", equivale metodologicamente à pedagogia de projeto de médias ou grandes proporções. Quando na sua forma pura, é totalmente negociado com o aluno e centrado neste - o que o torna inadequado para currículos pré-fixados, porém excelente opção para a pedagogia centrada no processo.

\subsubsection{Criação de material didático em leitura e produção}

A criação de material didático original é um assunto vasto e complexo, que mereceria um outro artigo em separado ou mesmo um livro para ser abordado em profundidade. Aqui trataremos somente de alguns princípios gerais, que podem ser aplicados a quase todas as propostas genuinamente comunicativas de ensino de línguas em situação de imersão, com exceção do programa-processo puro (que é, por conceituação, um programa singularmente determinado). O esquema a seguir opera uma síntese dos preceitos de Aebersold e Field (1997) para a leitura e de White e Arndt (1995) para a produção textual, unindo-os numa mesma perspectiva. 
Nosso ponto de partida será o jovem ou adulto com razoável automatização dos processos psicomotores e cognitivos da leitura e da escrita, ou seja, um aprendiz adolescente ou mais velho que pode se preocupar em processar significado diretamente, no nível de competência em que se encontra. A partir dessa fase, com a lateralização completa do processamento lingüístico e cognitivo, dois mecanismos básicos participam integradamente da construção dos sentidos: processos descendentes - do todo para as partes - e ascendentes - das partes para o todo. Aqueles, de natureza global, esquemática, também chamados de processos topdown, dependem do contexto e/ou do conhecimento prévio; estes, de natureza linear, serial, também chamados de processos bottom-up, dependem de regras sintagmáticas aplicadas às unidades processadas. Algumas tarefas cognitivas ou fases de tarefa (ou ainda outras variáveis, dentre as quais os estilos de aprendizagem) se caracterizam pela predominância de processamento descendente, enquanto que outras privilegiam mecanismos ascendentes. Quando dizemos predominância, isto obviamente significa que os mecanismos complementares, ainda que em segundo plano, não ficam excluídos.

Cabe ao professor, pois, estabelecer um roteiro de atividades didáticas que mobilize os processamentos descendente e ascendente de forma adequada. A esse respeito, é sabido que o conhecimento, a rigor, é um re-conhecimento que se modifica e se amplia constantemente (Santaella, 1998). Em outras palavras, não há processamento cognitivo sem conhecimento prévio, ou se quisermos, sem esquemas mentais prévios onde apoiar o que ingressa na mente pela percepção. Ora, se o conhecimento prévio e o contexto jogam um papel inicial fundamental na construção dos sentidos, e por sua vez estes dois fatores caracterizam o processamento descendente (top-down), deduzimos que o passo inicial em uma seção de leitura ou produção é um conjunto de atividades de natureza top-down, ou seja, trabalhar o conhecimento prévio e o contexto na relação que venham a ter com um texto já existente (leitura) ou que está para ser elaborado (produção). Mais adiante, o peso proporcional das atividades ascendentes ou bottom-up vai aumentando progressivamente, até que, a certa altura, as atividades estarão deslocadas agora da macroestrutura (o todo com suas partes mais imediatas) para a microestrutura (cada parte, examinada em função da maneira como os componentes intra e interfrásticos se organizam localmente para sinalizar os efeitos de sentido). Em ainda mais uma etapa, um trabalho de síntese e refinamento final leva de volta ao todo, mas um todo enriquecido por toda uma rede de padrões e metapadrões conectores, mais complexo do que se apresentava ao usuário (de forma real, ao leitor; virtual, ao escritor).

Os esquemas abaixo ilustram as aplicações desse princípio básico:

\section{ESQUEMA A:}

\section{PRÉ-ATIVIDADE — DO TODO PARA AS PARTES}

\subsection{Levantamento de idéias \\ q Brainstorming (fluxo de idéias) — pelo professor ou pelos alunos}


q Inventário reflexivo de questões centrado em conhecimento prévio - pelo professor ou pelos alunos

q Fazendo pesquisa bibliográfica ou tomando notas

q Usando informação icônica - tabelas, diagramas

q Usando role-play (dramatizações e assemelhados)

\subsection{Delimitação de idéias e parâmetros discursivos}

q Delimitando a idéia principal do texto e as idéias secundárias a partir do inventário anterior

q Estabelecendo o objetivo geral do texto

q Estabelecendo a imagem do leitor-alvo

q Levantando a estrutura básica do texto, incluindo a relação verbal-icônico, a diagramação, o suporte ou veículo, o contexto

q Estabelecendo a ordenação e articulação de idéias principais

2. ATIVIDADE CENTRAL - DAS PARTES ENTRE SI E DAS RELAÇÕES INTERNAS ÀS PARTES

2.1. A estruturação das idéias principais, suas idéias-suporte, as mútuas relações lógico-semânticas entre as idéias

2.2. O desdobramento das funções principais, suas funções-suporte, as mútuas relações entre as funções

2.3. As relações entre idéias, funções e formas - inclusive na articulação explícito-implícito

2.4. A construção dos sentidos na microestrutura textual, inclusive coesiva e lexical

3. PÓS-ATIVIDADE — DAS PARTES PARA UM TODO MAIS COMPLEXO

3.1. Para a leitura - trabalhando reflexivamente

q Estratégias retóricas

q Interfaces sócio-culturais

q Perspectivas ideológicas

3.2. Para a produção - revendo criticamente

q Relações texto-contexto

q Subdivisões textuais

q Coesão lógica e referencial e coerência

q Modalizações e posicionamentos

q Adequação de norma e de convenções gráficas

ESQUEMA B:

\section{LEITURA INTENSIVA}

\section{PRÉ-LEITURA}

q Mobilização de conhecimento prévio

q Geração de expectativas 


\section{LEITURA PROPRIAMENTE DITA}

1은'VEL — top-down (i) [ênfase na superestrutura]

- Idéia central e objetivo global

- Idéias secundárias e seus blocos semânticos

- Vocabulário

q separar palavras a conhecer e palavras a aprender

q estratégias contexto $\Rightarrow$ palavra

$2^{\circ}$ NÍVEL — top-down (ii) [ênfase na macroestrutura]

- Idéias-suporte - evidências, desenvolvimentos [item recursivo]

- Vocabulário

q estratégias multinível de "guessing" [gramática e estruturas]

q uso do dicionário se todas as estratégias de "guessing" falharem

a testagem de hipótese de significado

3№́VEL - bottom-up [ênfase na microestrutura]

organização gramatical — segmentação das sentenças

\section{PÓS-LEITURA}

REVISÃO E CONSOLIDAÇÃO DAS INFORMAÇÕES - sumário, outline, mapa semântico

DISCUSSÃO DAS INFERÊNCIAS - implícitos, modalizações, fato-opinião AVALIAÇÃO DO TEXTO — ideologia, estereótipos, pontos de vista, tom, registro, ironias

ATIVIDADES INTERTEXTUAIS — marcas lingüísticas, relações gênero-cultura RETROSPECTO DAS ESTRATÉGIAS DE LEITURA (METACOGNIÇÃO) VOCABULÁRIO - promoção de atividades para a criação de redes léxicoconceituais

q aplicação de palavras em atividades de paráfrase

q construção de textos próprios do mesmo gênero

q criação de textos de outros gêneros

q atividades de multicontextualização das palavras (poucas) para fixação na memória de longo termo

q atividades para uso de dicionários especiais (analógico, de sinônimos)

\section{ESQUEMA C:}

\section{ESCRITA-PROCESSO}

\section{ETAPAS}

1. PRODUÇÃO DE IDÉIAS - o que poderia ser escrito

2. DELIMITAÇÃO - o que exatamente vai ser escrito

3. ESTRUTURAÇÃO - superestrutura e macroestrutura

4. ESBOÇO - microestrutura

5. AVALIAÇÃO - controle de qualidade 
6. REVISÃO - aperfeiçoamento

A Escrita-Processo pode ser subdividida em:

Etapa 1 - Pré-Produção Textual

Etapas 2, 3 e 4 -Produção Textual

Etapas 5 e 6 - Pós-Produção Textual

Na prática, essas etapas não são rigidamente lineares: cada uma delas retroage sobre as demais e, nos casos particulares, pode haver refluxos, saltos, retornos cíclicos, atalhos. A linearidade se coaduna mais com a organização das atividades didáticas do que com a maneira de proceder de um escritor em situação real de produção. Em um processo gerador de textos, essas etapas fazem parte, mais precisamente, de um processo recursivo que perdura até que a versão definitiva tenha sido concluída. Nesse sentido, a "pós-produção", a rigor, não se situa depois da produção do texto, mas sim depois de concluída uma das várias versões pelas quais ele passa. Também pode ser feita uma subdivisão da escrita com base não nos processos cognitivos envolvidos, como acima, e sim em termos da tarefa de composição em si: planejamento e execução. Neste caso, do esboço em diante teríamos a escrita propriamente dita.

\section{BIBLIOGRAFIA:}

AEBERSOLD, J. A; FIELD, M. L. From Reader to Reading Teacher. Cambridge University Press, 1997.

CUNNINGSWORTH, A. Choosing Your Coursebook. Oxford: Heinemann, 1995.

DUBIN F.; OLSHTAIN, E. Course Design. Cambridge: Cambridge University Press, 1990.

ELLIS, Rod. SLA Research and Language Teaching. Oxford: Oxford University Press, 1997.

GARCIA, O. M. Comunicação em prosa moderna. 14ed. Rio de Janeiro: Ed. FGV, 1988.

RICHTER, M. G. Ensino do Português e Interatividade. Santa Maria: Ed. UFSM, 2000.

SANTAELLA, L. A Percepção: uma teoria semiótica. São Paulo: Experimento, 1998.

WHITE, R.; ARNDT, V. Process Writing. Longman, 1995. 